\title{
Corpos e experiências com demências: seguindo emaranhados de subjetividades e substâncias
}

Bodies and experiences with dementia: following tangles of subjectivity and substances

\section{Cíntia Liara Engel}

\section{OpenEdition \\ Journals}

\section{Edição electrónica}

URL: https://journals.openedition.org/aa/2351

DOI: 10.4000/aa.2351

ISSN: 2357-738X

\section{Editora}

Programa de Pós-Graduação em Antropologia Social (UnB)

\section{Edição impressa}

Data de publição: 1 dezembro 2017

Paginação: 301-326

ISSN: 0102-4302

\section{Refêrencia eletrónica}

Cíntia Liara Engel, «Corpos e experiências com demências: seguindo emaranhados de subjetividades e substâncias», Anuário Antropológico [Online], v.42 n.2 | 2017, posto online no dia 12 junho 2018, consultado o 18 maio 2021. URL: http://journals.openedition.org/aa/2351 ; DOI: https://doi.org/ $10.4000 / a a .2351$

\section{(c)}

Anuário Antropológico is licensed under a Creative Commons Atribuição-Uso Não-Comercial-Proibição de realização de Obras Derivadas 4.0 International. 


\title{
Corpos e experiências com demências: seguindo emaranhados de subjetividades e substâncias
}

\author{
Cíntia Liara Engel \\ UnB
}

No primeiro semestre de 2012, acompanhei algumas atividades do Centro de Referência para Portadores da Doença de Alzheimer, que faz parte do Centro de Medicina do Idoso (CMI) do Hospital Universitário de Brasília (HUB). Frequentei um grupo terapêutico para pessoas que foram diagnosticadas com Alzheimer nas fases iniciais, além de um grupo para treinar a memória e diminuir o ritmo do avanço da doença. Participei também de grupos de acolhimento e aconselhamento para cuidadoras de parentes que tinham Alzheimer ou algum diagnóstico composto de demência, em fases iniciais ou avançadas. E fui a algumas casas de pessoas que já não tinham condições de sair para a rua, ou mesmo de suas camas, por isso recebiam atendimento domiciliar. ${ }^{1}$

A maior parte das pessoas que conheci tinham um diagnóstico de demência por "provável Alzheimer", ou mista, prevendo "provável Alzheimer e provável demência frontotemporal". Ou, ainda, uma demência mista composta de demência vascular com "provável Alzheimer" ou com "provável demência frontotemporal". A feitura de diagnósticos da demência é complexa (Engel, 2013; Feriani, 2017). Envolve exames de imagem, testes cognitivos e entrevistas com diversos profissionais sobre os tipos de dificuldades enfrentadas no cotidiano. Os exames servem para descartar ou afirmar uma demência vascular, ${ }^{2}$ já que o Alzheimer e a demência frontotemporal não conseguem se provar em resultados de exames, pelo menos não no Distrito Federal em 2012.

É possível, diziam em meu campo e em alguns livros que li, ter certeza das provas físicas dessas doenças se for encomendada uma autópsia depois da morte do sujeito. Por isso os diagnósticos são adjetivados como "prováveis"; não há uma prova concreta que estabeleça sua certeza laboratorial e patológica. E esse fato não os torna menos reconhecidos, pois são diagnósticos clínicos. Além disso, de acordo com a literatura especializada, uma autópsia pode não encontrar os substratos físicos da demência, ou ainda, a quantidade de dano físico pode não ter uma relação direta e inequívoca com a fase da doença. Existem manifestações físicas distintas, o que torna o processo de "prova" laboratorial uma investida complexa e aberta a pesquisas e investigaçóes (Lock, 2013). 
Optava-se, em meu campo, pelo diagnóstico de demência causada por Doença de Alzheimer (DA) quando se ouviam queixas sobre a memória e dificuldade progressiva em realizar tarefas diárias. Ou seja, não era suficiente estar esquecido, era necessário que um aumento na dependência de outras pessoas para realizar atividades cotidianas fosse relatado por pessoas próximas. A demência frontotemporal era aventada quando a reclamaçáo maior era em relação ao comportamento "inadequado" do sujeito diante dos outros, mesmo que essa também fosse uma possibilidade para o Alzheimer. Havia, então, um manejo de pesos entre comportamentos, esquecimentos, delírios e dificuldades com atividades básicas e instrumentais da vida diária. Em alguma medida, o diagnóstico atendia às reclamaçóes das pessoas que procuravam o Centro e era composto em conjunto para suprir alguma demanda cotidiana acerca do que estava desorganizando o mundo e o convívio dos sujeitos e o que precisava de tratamento e cuidado. De acordo com Graham (2006), existem algumas variaçóes na forma de diagnosticar, especificar e tratar demências dependendo do local, país e tipo de especialista, mesmo havendo uma padronizaçáo de instrumentos.

Em relação aos sujeitos que tinham o diagnóstico para si, conheci e convivi com aqueles categorizados como tendo "provável Alzheimer". Já de cuidadoras, conheci diversos casos, mas todas tinham um diagnóstico de alguma demência para seus parentes e um envolvimento com a lógica terapêutica do CMI. Ou seja, é desse universo, ou do contato com esse universo, que falo. Nele, a existência de um diagnóstico é fundamental para que se participe, assim como o reconhecimento coletivo e familiar de que existem questóes que desviam o sujeito de sua normalidade e de uma normalidade tida como razoável pelos que estão em sua volta. Alguns desses desvios ficam mais conhecidos do público e dos médicos que fazem diagnóstico, como a perda de memória; outros são incômodos frequentes, muitas vezes ignorados em manuais de diagnóstico e na veiculação sobre a doença, mas que podem estar citados em livros mais densos sobre o assunto, discutidos por médicos mais experientes e por cuidadoras: dificuldades com visão, olfato, paladar e sentido.

A centralidade patológica sobre o funcionamento do cérebro e o próprio cérebro lido como entidade subjetiva é parte de um debate importante para os estudos da antropologia da demência, especialmente interessados em historiografar a aparição da doença como entidade articuladora de experiências e das disputas que envolveram (e continuam envolvendo) a diferenciação do que seria, de um lado, o envelhecimento normal e, de outro, as demências (Fox, 1989; Leibing, 1999; Lock, 2013). Tais estudos têm lidado com uma disputa complexa sobre fisicalidades e manifestaçóes de sintomas lidos como doença. A despeito do 
investimento em pesquisas, a disputa não se fecha e os corpos tendem a não cooperar com a aceitação de explicaçôes simples e localizadas (Lock, 2013).

O que acontece é que a fisicalidade do Alzheimer, ao mesmo tempo em que é evidente para pesquisadores e profissionais de saúde, não é óbvia, não é de um tipo só e não causa consequências lineares em termos de sintomas. Isso faz com que a ontologia da doença e as decisóes sobre tratamentos estejam abertas e envolvam debates ferrenhos entre teorias que localizam a doença em um tipo de causa em cadeia de dilemas orgânicos e outras mais abrangentes e ambientais, que pensam causas e consequências em termos mais interconectados (Lock, 2013). No âmbito da pesquisa patológica, apesar de os debates serem ferrenhos, especialmente quando precisam conquistar recursos, há uma geral aceitação - ou uma impossibilidade de negação - da complexidade de relaçóes entre causas ambientais e orgânicas e das muitas fisicalidades envolvidas. A busca por explicaçóes fisicalistas, nesse caso, não é necessariamente redutora; ela está imersa em embates que podem ser mais restritos ou abrangentes (Ballanger et al., 2009; Lock, 2013).

Apesar de se lidar com um contexto no qual seria evidente e frutífero dialogar com trabalhos sobre constituição de narrativas hegemônicas, discursos e subjetividades nas quais as manifestaçóes do self são conectadas com certo paradigma "cerebralista" (Azize, 2011; Rose, 2007; Vidal \& Ortega, 2017), o campo do Alzheimer póe em jogo constante esse próprio paradigma. ${ }^{3} \mathrm{Se}$, por um lado, afirma-se que a demência balança a subjetividade dos sujeitos porque existem danos no cérebro - e isso parece nos denunciar a centralidade do cérebro na potência de manifestação do self -, por outro, Lock (2013) acompanha como muitos investimentos em pesquisa empírica e seus resultados controversos continuam tornando difícil a estabilização da doença e da manifestação de sintomas em marcadores físicos, apesar de ser também impossível negá-los. Também é complexo estabelecer um padrão comparativo de normalidade no envelhecimento. Afirma-se que pessoas com Alzheimer possuem em seus cérebros placas e emaranhados, além de outros marcadores; nem todas as pessoas que possuem placas e emaranhados desenvolvem Alzheimer, pois existe uma porcentagem insistente de pessoas que, mesmo com placas e emaranhados, não apresentam sintomas da demência durante a velhice. Ademais, não é possível associar a gravidade dos sintomas ao tamanho do dano no cérebro.

Existe ainda outro debate sobre a manutenção do sujeito na doença de Alzheimer que encontra feituras distintas, desde o que se poderiam chamar de estudos sobre personhood (Chatterji, 1998; 2006; Kontos, 2005; Leibing, 2006, 2017) até investidas brasileiras de pensar um "devir-demente" (Feriani, 2017; Vianna, 2015). Tais trabalhos precisam lidar tanto com uma narrativa de 
que os danos no cérebro matam o sujeito como com narrativas de que expressóes comportamentais e de falta de memória matam o sujeito. Dar escuta aos sujeitos envolve repensar a importância do cérebro na caracterização deles, mas também da normalidade e razão - independente de como essas coisas são associadas e em qual nível.

Dado esse contexto, minha estratégia aqui é colocar as materialidades também em jogo sem tomar o que o cérebro significa ou deixa de significar em narrativas como ponto de partida. Ademais, não vou colocar em questão as narrativas, interpretaçóes ou afirmativas de que existe algo novo (e agoniante) com o corpo e algo novo com o sujeito. Vou tentar, entáo, seguir essas novidades que desestabilizam experiências e que foram nominadas de demência. Com isso, tento promover alguns jogos reflexivos em torno de noçóes fundamentais desse campo, como subjetividade encarnada, corpo que se organiza em subjetividade e diversidades orgânicas.

Isso porque ouvia em campo e me convencia, com meus interlocutores, de que tinha algumas coisas novas com o corpo, e achei importante expressar isso também com a etnografia. Acredito que a descrição etnográfica da dissertação traz à tona esses elementos (Engel, 2013). O exercício deste artigo, no entanto, é (re) fazer uma descrição etnográfica estabelecendo diálogos reflexivos com diferentes interlocutores. Vou bricolar chaves teóricas que me fizeram (re)ver o caderno de campo, tentando com isso (re)descrever a composição de corpos, as experiências e os engajamentos materiais com o mundo.

Em suma, o objetivo deste artigo é dialogar com experiências, seguindo novidades e desafios de engajamento em relaçôes, com o próprio corpo e com o ambiente e, a partir deles, refletir sobre a composição de subjetividades e organicidades. Inicio pela discussão de como poderia ser interessante pensar com a ideia de uma subjetividade encarnada para dizer algo sobre essas vivências todas com o Alzheimer. Percebo, contudo, que algumas coisas deixam de ser ditas e que pensar em como o corpo se organiza em subjetividade e se engaja no mundo abre outros caminhos. Tento debater com a ideia de um organismo que possui um funcionamento normal necessário para estar no mundo, olhando para as desorganizaçóes desse funcionamento, o que me faz também pensar em agenciamentos, vontades e engajamento do corpo que transcendam determinadas ideias de organismo, sujeito e mundo. Passo, então, a tensionar essas outras existências e mundos compartilhados a partir de corpos que resistem a tentativas denormalização. Faço isso dando espaço para as várias disputas envolvidas nesse processo. 


\section{Uma subjetividade encarnada}

Não raro, o corpo em sua organicidade é deixado em um segundo plano nas análises das ciências sociais. Para Henrietta Moore (2007), alguns trabalhos da antropologia contemporânea superam a ideia de que a cultura é incutida em corpos pré-existentes e, mais que isso, propóem-se a dialogar com a organicidade dos corpos. A autora discute, ainda, recentes trabalhos de neurobiologia que defendem a perspectiva de um corpo somático, afirmando que a organicidade como um dado a priori e fixo tem sido superada por diferentes campos de conhecimento. A relação entre cultura e biologia é, no lugar disso, uma amálgama: cultura e biologia seriam ontologicamente relacionadas. Nessa perspectiva, investir em grafias das organicidades não significa ser capturado por uma perspectiva fisicalista e, necessariamente, reducionista, mas disputar as feituras ontológicas delas.

Moore (2007) preocupa-se, especialmente, com o problema clássico da aquisição da cultura e das relações entre corpo, mente e mundo, partilhando do objetivo de compreender como indivíduos se constituem como seres sexuados dentro de diferentes universos culturais. Seu objeto, então, é não somente as constituiçôes de gênero, mas também a feitura de corpos sexuados. Para tanto, a autora assume o desafio de casar uma teoria psicanalítica da aquisiçáo de subjetividade - que envolve pensar em formação do desejo, imaginário, identificação, resistência, inconsciente e self - com teorias antropológicas da aquisição da cultura. Ela defende que uma teoria acerca da constituição do sujeito é fundamental para pensar a sua questáo.

Em sua perspectiva, buscar uma teoria do sujeito permitiria falar tanto de aquisição e cristalização de normatividades como de resistência e multiplicidade, porque tal teoria abarcaria: (i) o processo que possibilita a constituiçáo de sujeitos de modo culturalmente variável, o que envolve um investimento compreensivo em como linguagem, experiência e mudança social se relacionam; (ii) o fato de que indivíduos se constituem de seus múltiplos posicionamentos enquanto sujeitos, emergindo em discursos e práticas que são conflituosas, contraditórias e dependentes de configuraçôes sociais de poder e ideologia. O self é, entáo, formado desses múltiplos posicionamentos; (iii) existe uma parte do self que escapa à determinaçáo, e isso pode ser teorizado com o auxílio dos conceitos psicanalíticos de desejo, fantasia e inconsciente.

A autora concorda com a tese de Strathern (1992 apud Moore, 2007) de que os processos de engajamento e interpretação dos indivíduos sobre práticas culturais revelam um self criativo, mas que fala e existe por meio de determinado idioma cultural. Moore insiste que indivíduos representam e interpretam sua experiência, e produzem fantasias que os engajam no mundo. Isso ocorre tanto 
de forma consciente e julgada como inconsciente. Esse processo se dá em termos de determinada linguagem, de determinado mundo cultural e de possibilidades materiais de envolvimento. Mais do que uma relação apenas com a linguagem, existem produçóes de sentido advindas de engajamentos corpóreos em mundos. Contudo, o engajamento no mundo pela prática corpórea circula, assim como a linguagem, entre fantasia, desejo e inconsciente, de modo que não é possível, para a autora, compreender um self criativo, a capacidade de agência e a resistência sem dar conta de motivaçóes inconscientes. Só tendo em conta tais elementos poderse-ia compor uma teoria da aquisição de subjetividade.

Moore tem a cautela de não fixar essa teoria da aquisição de subjetividade em determinado período etário, aprisionando o sujeito em uma constituição fixa; fala, em vez disso, em um processo nunca finalizado de becoming a subject. Dá um passo importante ao defender cultura e biologia como amálgama em movimento, pensando como normatividades se fazem em substâncias e criam organismos. São, de alguma forma, interiores ao corpo, mas náo por um processo condicionante de interiorização que entende substância e organismo como fixos e dados. É, no lugar disso, um corpo somático.

Vou adensar, com o encadear das seçóes seguintes, as ideias de substância e organismo aludidas aqui. Vale já evidenciar, contudo, que, quando falo em organismo, trata-se de uma organização tida como necessária de todas as substâncias em relação viva. Substância aqui não é a essência da coisa, mas elementos diversos que possuem certa quantidade de qualidades que, em contato com outras, mudam, se reorganizam e criam.

O espaço dado por Moore (2007) permite outro status analítico para o corpo, mas me parece que seu foco está em atentar para um sujeito encarnado, não para o corpo. Não tenho razáo para discordar dessa perspectiva, é uma interpretação bem situada no projeto de compreender corpos se fazendo sexuados, mas é um desafio adaptá-la ao que preciso dizer. Observando pessoas morrendo, ou pessoas que têm cérebros cujos neurônios estão morrendo, ou ao menos não estão se conectando pelos mesmos caminhos e com a rapidez anterior, o desafio é mais o de saber como a carne se organiza em subjetividade do que como o sujeito é encarnado. Ao perder carne, ou mudar a organizaçáo da substância, existem consequências para o sujeito que não se resumem a morrer ou a deixar de possuir um self. É um deslocamento do olhar - pode ser só um detalhe, mas acho que é mais do que isso.

Antes da doença, as pessoas agiam no mundo, consciente ou inconscientemente motivadas, e eram lidas, em suas personalidades, em diferentes contextos. Mas, com o avanço da doença, algo essencial parece mudar. Marcos, ${ }^{4}$ um cearense 
de pouco mais de 60 anos, muito magro e alto, com semblante e fala calma, era casado com Alda desde a juventude. Havia sido diagnosticado com "provável Alzheimer" em fase leve. Alda um dia contou ao grupo de cuidadoras que estava tendo uma recorrente discussáo com o marido por conta de um desentendimento. Ele viu um beijo entre ela e um amigo na despedida de um jantar que ocorreu na casa deles. Ficou muito ofendido, gritou com Alda, xingou-a de "sem-vergonha" e a ameaçou, dizendo que faria uma ligação para os irmãos dela contando toda a história. Ainda terminou a briga dizendo: "disso eu não vou esquecer!"

Marcos não era particularmente ciumento, de acordo com Alda, mas ela entendia que um beijo romântico em sua casa e em sua frente poderia ter causado tal reaçáo no marido. Alda nos contou, contudo, que o beijo que ele viu foi no rosto e de despedida, não tinha nada de romântico. Ela explicou isso ao marido e ficou também chateada, porque achava que ele tinha visto o que ocorreu, náo entendia como ele poderia ter enxergado outra coisa. Ele, contudo, acusou-a de ter tentado persuadi-lo da verdade.

Alda achou que a ameaça do marido de não esquecer isso poderia não se realizar, já que ele tinha Alzheimer, mas, para sua falta de sorte, ele se lembrava do ocorrido com certa frequência. Havia dias em que retomava a história e brigava com ela; em outros, era como se não tivesse acontecido. Não se sabe como Marcos viu o que aconteceu, se viu algo que não estava explicitamente expresso, se interpretou de uma forma pouco justificada algo que viu ou se passou a entender beijos no rosto como interação romântica. Náo se sabe também por que essa informação ele decidiu não esquecer e por que, de fato, não a esquecia em boa parte dos dias.

Fato é que a interação de Marcos estava atravessada por algo outro que sua personalidade ciumenta, ou por uma ofensa reconhecida por ambas as partes. Havia mudado algo também em como interpretava o mundo, ou até em como via as coisas. Em termos de personalidade, ouvi gente reclamando que seus parentes tinham mudado traços que lhes eram caros, mas também comentários de que determinados aspectos da personalidade ficaram mais evidentes, ou aguçados. De toda forma, parece consenso que havia mudado algo muito sério em como essas pessoas se apresentavam no mundo, em como julgavam os fatos, se posicionam, amavam e sentiam ciúmes. Havia mudado algo em termos do sujeito e das interaçóes.

Parece evidente que confusóes com a memória ou até com os sentidos mudam e podem atrapalhar o raciocínio, e talvez até a personalidade. Talvez elas atrapalhem a possibilidade de existir analiticamente um sujeito, mas apenas se pensarmos que existe um sujeito anterior, que era dono de uma subjetividade 
que lhe definia, e que agora não é mais. Ademais, apenas se a agência for tomada em sua dimensão consciente, sem ter em conta como o desejo forma e é formado do inconsciente. Isso envolve tanto um sujeito fixo como racional, e parece que Moore é um dos exemplos contemporâneos que permite pensar em um sujeito e em um self criativo que movimentam relaçóes consciente e inconscientemente motivadas. Poderíamos, assim, continuar falando em termos de uma teoria do sujeito quando observamos o exemplo de Marcos. Parece-me que uma teoria de um sujeito encarnado com motivaçóes da ordem do inconsciente resolve alguma parte do problema, mas não sei se é suficiente. Assim sendo, julgo necessário trazer o corpo para protagonizar a tentativa de compreender as experiências com o Alzheimer.

Pia Kontos e alguns parceiros (2005; Kontos \& Naglie, 2009; Kontos et al., 2011) têm feito um exercício nesse sentido ao produzir sobre a Doença de Alzheimer: fazer o sujeito aparecer em escrita etnográfica a partir dos desejos expressos pelo corpo e de como esse desejo e saber do corpo, ele mesmo, é composto pela sociedade que o circula. Em diálogo com os estudos que investem tinta nas manifestaçóes da pessoa - personhood -, chamam atenção para as tecnologias de diálogo e cuidado que vão se fazendo na interação com pessoas com demência. Questionam a centralidade da linguagem e da memória para definir - e, no caso da demência, negar - a subjetividade e manifestação da pessoa. Esse corpo, então, é olhado pelas suas manifestações de desejo, comunicaçóes e cooperação. Esse tem sido um movimento muito importante no debate antropológico sobre o Alzheimer, mas, como Leibing (2017) sublinha, a ânsia por "(re)encontrar" o sujeito e olhar para as manifestaçôes de desejo, por vezes, se faz no movimento de negar ou deixar de lado as dificuldades de comunicação, sintomas e dilemas - especialmente quando um cuidado total e atento náo é possível. Vou tentar, então, testar outro rumo reflexivo: que corpo é esse, que sintomas são esses e o que mesmo é a experiência subjetiva com o corpo?

\section{O corpo e a experiência subjetiva}

Por vezes, quando lemos sobre as demências e especialmente sobre a Doença de Alzheimer, a memória vira um grande acumulador do debate, junto com as alucinaçôes, os comportamentos chamados de desviantes e uma série de dilemas classificados como cognitivos. Esse é um protagonismo narrativo, o que chama mais atenção, e também uma parte fundamental da experiência, mas por ora vou abordar outros aspectos que dialogam diretamente com novidades em termos da percepção de mundo, dos sentidos e das interconexóes disso com esquecimentos, delírios e agonias (Engel, 2013). Há algo sério em termos do que se enxerga. 
Mariana, uma senhora de 65 anos, ruiva e rápida de raciocínio, mesmo com o diagnóstico de provável DA, reclamava muito que não estava vendo as coisas como os outros, ou como costumava ver. Às vezes, ela via tudo dobrado, ou com uma ordem que lhe parecia estranha. Era difícil ler números, ou escrever. Eu a vi jogando bingo e tentando desenhar um relógio. No jogo do bingo, ela achava irritante e difícil acompanhar os números cantados, porque não os enxergava. Se chamassem o número 13 , por exemplo, ela via o 1 e via o 3, mas eles náo significavam mais o 13. Para o jogo do bingo, precisava que outra pessoa a auxiliasse a enxergar os números.

Quando foi tentar desenhar um relógio para uma atividade proposta pela equipe, teve uma dificuldade inicial em posicionar o lápis. Não conseguia chegar até o papel, era desafiador conectar as duas superfícies. Depois, desenhar números dentro de um círculo e posicioná-los era muito complexo, assim como escrevê-los. Ao tentar fazer o 3, mudou o lado das pontas e fez o 5. Quem percebeu isso foi ela própria: "gente, eu fui tentar fazer o 3 e fiz foi o 5 ".

Mas também parecia haver um caminho contrário das afetaçôes. No dia em que Laíz, senhora ágil de corpo e tímida com as palavras, esqueceu os óculos, foi muito mais difícil manter uma conversa, e ela se esqueceu também da cor do seu avental. Todos os participantes do grupo de treinar memória tinham um avental com uma cor que escolheram e que era representativa de algo muito importante em suas vidas. Laíz, nessa época, costumava lembrar sua cor com uma ou duas dicas, mas, no dia em que esqueceu os óculos, não lembrou. Ouvi ainda a reclamação de uma cuidadora de que sua mãe havia piorado muito da memória depois que perdeu parte da visão por conta da catarata.

Esta outra aproximação com o mundo não era só da ordem da visão. Outra senhora, Luzia, reclamava muito de ter parado de sentir o cheiro das coisas. Ela sempre estava no CMI com o marido, com quem tinha um relacionamento muito próximo e aproveitava o cotidiano de sua casa. Por conta da dificuldade com o olfato, ela não conseguia mais cozinhar, porque deixava tudo queimar, e era perigoso que esquecesse o fogáo ligado. Comer ficou bem menos prazeroso também. Ouvi uma cuidadora dizer que descobriu a doença da mãe porque ela estava salgando demais a comida, mas continuava náo sentindo o sal; havia perdido parte do paladar. Essas questóes representavam dificuldades para manter um cotidiano partilhado na lógica das relaçóes afetivas e familiares, e foram elas que sinalizaram vontades de buscar um médico.

Manter uma conversa com quem quer que fosse também tinha lá seus desafios. Em um dia, uma das senhoras, Maria Joana, estava impressionada com uma reportagem que tinha visto pela manhã, sobre uma mãe que matou o bebê 
que acabara de parir. Achou um absurdo, lembrou-se de quando chegou em Brasília com o marido e seu primeiro filho. Um dos homens presentes tentou pensar sobre como a mulher poderia estar passando por muitas dificuldades, sugerindo que talvez aquele fosse um ato de desespero. Outra senhora, Luzia, interveio falando que um dos seus filhos nasceu em Brasília, em uma época em que ela tinha dificuldades. Laíz, que também acompanhava a conversa, olhou para Luzia com surpresa e perguntou: "você tá grávida?” Luzia deu risada e disse: "não, minha filha, daqui não sai mais nada". Mudaram de assunto logo depois de algumas risadas.

Havia também dificuldades com as palavras. Um dia, Luzia queria nos contar que havia escolhido a cor amarela para o seu avental por conta de sua aliança. Ela disse que o amarelo representava uma das coisas mais importantes de sua vida, que, por sua vez, era representado pela a... olhou para o dedo, massageou o lugar onde a aliança costumava ficar e disse: "é amarelo por causa da Alessandra" [...]. Não, é por causa da ali...”; alguém a ajudou a lembrar a palavra depois. Ela reclamou ao grupo que era comum que isso acontecesse: queria dizer uma coisa, mas acabava dizendo outra. Uma senhora do grupo de cuidadoras de pessoas em estágio mais avançado disse que a mãe, quando quer comer, diz "vamos nhamo, nhamo", usando uma onomatopeia para dizer o que queria sem a palavra que seria usualmente utilizada por ela.

Acessar a memória para compor uma fala, um raciocínio, uma movimentação qualquer parece se diferenciar para os que recebem o diagnóstico dessa doença. Isso envolve uma dificuldade tanto de lembrar todos os elementos para manter uma conversa fixada em um tema, prestar atenção nesses elementos e associá-los ao objetivo da conversação, como também para organizar uma semana, saber quem são as pessoas com quem se está convivendo, ou melhor, quem elas eram antes. Com o avanço da doença, é comum que as pessoas conheçam bem quem está em seu cuidado cotidiano, mas náo a conectem necessariamente com quem a pessoa foi antes da doença - uma filha virou mãe, ou "aquela moça chata que manda em mim”. Também, com o avanço, fica difícil fazer atividades físicas, coordenar movimentos para determinado objetivo e, quando o quadro se agrava mais, saber o que fazer das vísceras para conseguir defecar.

Desses exemplos, parece possível afirmar que muita coisa depende desse diálogo elétrico entre neurônios, mas não de forma categórica, causal e simples. $\mathrm{Ou}$, de outra forma, desequilíbrios na substância orgânica ou em seu modo de se relacionar têm consequências diretas nos modos de existir, sentir e se relacionar dos indivíduos, inclusive em coisas que pareciam ser de ordem inata ou dada, como defecar. Parece também que órgãos não são distantes e divorciados em seu 
funcionamento. Sentidos, cérebro, intestino, todos têm um diálogo interafetado, por assim dizer. Se a troca de sinapses atrapalhada afeta a visão, por exemplo, a perda de visão piora a memória, em alguns casos.

Parece que mudanças na substância orgânica promovem, por fim, mudanças na própria dimensão de estar no mundo. $\mathrm{O}$ mundo não é só conectado com o imaginário e o mundo inconsciente que produziram o sujeito e o encarnaram; é conectado também com carnes e com suas qualidades. Descola (2014) afirma que, para pensar antropologicamente, é necessário pensar em ontologias, é necessário pensar em processos de constituiçáo de mundos. Afirma que existe um conjunto de qualidades dos objetos e seres que são predicados ontologicamente nesse processo de fazer mundos. Mundo e natureza, assim, não são formados de objetos e seres que representam ideias prontas para serem capturadas por nosso intelecto, nem construçóes sociais feitas em cima de um material cru. Fazer mundos é escolher e acentuar algumas dessas qualidades e ignorar outras, é criar naturezas-culturas das quais o ser faz parte. O ser é no mundo em que habita, e o mundo que habita é um processo de feitura de mundo.

Descola (2014) fala de culturas e mundos para coletivos e da relação entre natureza e cultura. Merleau-Ponty $(2006,2015)$ pensa essas questóes no nível do corpo, que é seu limite metodológico para pensar o ser. $\mathrm{O}$ autor vê o corpo como campo de experiência que se engaja a partir de sua unidade perceptiva, formada pelo todo de sentidos e afetações com o espaço e os outros. A interação se dá na relação original, sempre no presente. A capacidade de apreender melhor, isto é, de experimentar um mundo e uma relação, é de ordem pré-objetiva. Ou seja, não são categorias de pensamento, memória e aprendizagem que explicam e causam como o ser vive, experimenta e pensa. Isso não quer dizer que a sociedade ou a cultura sejam irrelevantes; o mundo é materialmente composto pela cultura e pela sociedade, o original da experiência perceptiva é situado em mundos culturais e intersubjetivos. Ideologia é mundo material e experiência é relação e engajamento com esse mundo.

Não é necessário, como entendo, perder de vista linguagem, mito e discurso. Para Haraway (1991), teorias são encarnadas. Corpos, em sua perspectiva, são feitos organicamente em contextos e dentro da linguagem e de seus mitos. Contexto, para ela, náo é um dado por si, mas sim uma coestrutura, um cotexto, e a linguagem, assim, é um tipo de engajamento. Disso entendo que mitos, teorias, linguagem impregnam nas materialidades e são, assim, materialidade também. Discurso e composição mítica de corpos é também sua possibilidade de existência, já que o mito é ao mesmo tempo orgânico, tecnológico e textual. Não há algo anterior; é tudo sempre um compósito. Interpreto da leitura que 
mito, ou teoria, são carnes em relaçáo. E, engajados no contexto industrial e pós-industrial, somos compósitos de mitos científicos e biomédicos, mas esses mitos não são unificados. Discursos científicos disputam corpos e materialidades, são multilocalizados e fazem narrativas ficcionais poderosas. Ciência, assim, é cultura. Dialogar com as muitas disputas dentro da biomedicina, aqui, é também dialogar com a materialidade em operação.

A perspectiva da fenomenologia de Merleau-Ponty (2006) é essencialmente relacional. $\mathrm{O}$ corpo não é uma essência fixa, um todo de sentido dado; ele se faz no e do mundo, ele apreende no diálogo de qualidades que se afetam. Ele é impulsionado, se engaja e, assim, cria, aprende, objetiva a partir de determinada linguagem. Mas a linguagem é algo separado da experiência apenas se for tomada como estruturada e racionalmente pautada, pois o ato comunicativo da fala vocalizada é também da ordem perceptiva. A intenção da fala é parte do engajamento, mesmo que talvez as palavras e seu ordenamento em sentenças não sejam.

O corpo, assim, é contíguo ao mundo. Mas, em Merleau-Ponty (2006), é também substância, na medida em que adoece, perde membros e morre. O corpo é um ponto de partida metodológico, o ponto de vista que faz aparecer o que é real. O corpo é condição de existência do mundo, o que faz com que o real seja contingente ao corpo. O real é muito importante para o autor: "[...] o que me interdita tratar minha percepçáo como ato intelectual, é que um ato intelectual captaria o objeto como possível ou como necessário, e ele é, na percepção, real [...]" (Merleau-Ponty, 2015:36).

Pensada a partir dessas ideias, a noção de substância não deve fixar o que é o corpo, como se os compostos orgânico-químicos fossem mantenedores do mesmo material, ou natureza, além de fechados em si mesmos. Mas o corpo perece e, como sujeito é corpo enquanto campo perceptivo, isso tem consequências ontológicas.

Ingold (2011) defende que a antropologia trata das condiçôes e dos potenciais relativos à vida. Vida, em sua concepção, não é um caminho fechado e prédefinido, mas uma multiplicidade de estratégias e caminhos abertos que se formam e conectam. E essa vida não é formada de uma estrutura genética fixa que permite ou náo estabelecimentos de um ser, ou de uma pessoa. Seres, humanos, animais, mundos estão em processo de se fazer constantemente. Ingold sugere falar em "human becoming", "person becoming", "animal becoming", "plant becoming", todos em um processo constante de afetação, entrelaçamento e composição de caminhos e fluxos históricos. Seres e espaços compartilham do tempo e se fazem em conjunto. Organicidades emergem continuamente dentro de mútuas relaçóes condicionantes. 
Penso que, ao falar de substância, estou de acordo com essa perspectiva do autor sobre a matéria e, ainda, interessada em falar sobre a vida e as formas de habitar e coabitar. Entendo, assim, substância como um agregado de elementos que se apresenta de uma forma ou outra em determinadas condiçóes de afetaçáo e, sendo assim, pode se compor de novos elementos, perder elementos, se transformar em outra coisa a partir da interação e, mesmo assim, se tratar de substâncias. Elas se relacionam e em relação condicionam. Não há como observar formas de habitar sem pensar nesses condicionantes de substância, ao mesmo tempo em que seria demasiado incompleto buscar pela essência substantiva que condiciona determinado ser em seu corpo pouco permeável que age em um mundo oco.

Como a substância se apresenta, então, afeta - de forma não linear e padronizada - sujeito, subjetividade, self e mundo. Estabelece contingências. Talvez até esses termos sejam de difícil uso, trazendo o corpo fenomenológico e a prioridade da experiência (a não ser com muitas ressalvas, as quais não tenho espaço para fazer aqui). Para Merleau-Ponty, a subjetividade é um engajamento temporal das impulsionalidades do ser se projetando no mundo e estabelecendo com ele uma relação a partir do presente, em termos do passado e para o futuro: "para nós a síntese perceptiva é uma síntese temporal; a subjetividade, no plano da percepção, não é senão temporalidade, e é isso que nos permite preservar no sujeito da percepção a sua opacidade e sua historicidade" (Merleau-Ponty, 2006:321). Existe vontade, impulso original, e existe subjetividade na relação e afecção com o tempo e com os outros a partir do presente, criando o presente e se projetando com o passado e para futuros. O tempo existe e faz parte do campo perceptivo e do corpo, compondo história e fazendo subjetividades.

A mudança de substância, nesse contexto de corpo no mundo e subjetividade para o mundo, tem consequências ontológicas, mas não desarticula impulsos e engajamentos. Na perspectiva do autor, para entender corpos adoentados, é necessário que fisiologia, mente e mundo não sejam divorciados e que se pense em várias maneiras de ser corpo e de ser consciência. $\mathrm{O}$ corpo sempre representa a contingência, e o real é sempre contingente. Para o autor, apenas ignorando a loucura e a experiência dos sonhos poder-se-ia imaginar o mundo como realidade dada. Ao mesmo tempo, adoecidos não se divorciam do mundo; formam-no em uma relação contingente àquele corpo, àquela substância.

Para Merleau-Ponty (2006), somos obcecados pelo mundo nos sonhos e a loucura gravita em torno do mundo. Ou seja, há algo como que um mundo próprio do indivíduo, mas dentro de conexóes intersubjetivas, que, ainda, se relacionam com determinado espaço, tempo e materialidades. Existem, nesse sentido, intermundos. Pensando com Ingold (2011), seres habitam, suas formas de 
habitar e viver formam e são formadas de determinadas paisagens e possibilidades de entrelaçamentos. Em alguma medida, são essas coabitações e entrelaçamentos que traçam mundos. Apesar de ter algo do sujeito e da consciência que é inacessível, existem conexóes e interafetaçóes que tornam o processo de fazer mundos sempre um processo coletivo. São, assim, intermundos.

Isso se comunica com o que foi trazido com a descrição etnográfica. Esses sujeitos dependem de sua substância para estar no mundo, fazem mundos com ela, se engajam com ela em relaçóes e em cotidianos. Acessam outros mundos, sua desordem física os afeta ontologicamente, mas não os divorcia de se relacionar com as qualidades que outros próximos também se relacionam e, ainda, com esses outros e suas afetaçóes e/de substância.

Quando passamos a assumir tipos de mundo e consciências que tentam estabelecer comunicaçóes a partir de intermundos, ser e sujeito passam a representar corpos engajados nesses intermundos, ou ainda formas de habitar e viver em corpos entrelaçados. Subjetividades são engajamentos dados a partir do presente, e náo formatados pela memória. Projetam-se com ela de modos distintos e, assim, é possível falar analiticamente em textos acadêmicos de sujeitos e subjetividades em portadores da Doença de Alzheimer, assim como a vivência em mundos intersubjetivos.

Pensar sujeito me parece ainda relevante neste trabalho, especialmente em contraposição a uma narrativa insistente sobre o Alzheimer que afirma que há como deixar de ser sujeito quando se perdem funçôes do cérebro. Trazer o corpo para protagonizar a descrição, contudo, me pareceu uma forma de falar de mais detalhes sobre a experiência que não seriam aventados com uma teoria do sujeito, mesmo aquela proposta por Moore (2007), ou ainda com a busca da expressão do sujeito nos engajamentos desejosos do corpo (Kontos, 2005). Apesar disso, tentando dialogar com a experiência dos que conheci, também não abandonaria a relevância de pensar subjetividade, sujeito e self. Gosto da ideia de subjetividade na relação do corpo com o tempo, fazendo assim história. Também trago a permeabilidade do corpo que é, sempre, um processo, constantemente organizado e provocado no ato perceptivo. São outras tonalidades da experiência as aventadas para poder falar de sujeito aqui.

Parece-me que pode ser complementar, dentro dessa lógica, pautar e produzir a partir de uma diversidade de corpo e potência de existência de corpos, organicidades em movimento e articulação. Referências importantes para esse tipo de raciocínio têm se formulado com o movimento anticapacitista dos estudos de deficiência (Diniz \& Barbosa, 2010; Kafer, 2013), o movimento pela neurodiversidade, pensado por autistas (Singer, 1999), e alguns debates contemporâneos sobre a 
vida com doenças crônicas (Engel, 2013; Fleischer, no prelo), os quais chamam atençáo para a ampla necessidade de cuidado nos processos de vida e morte e para como a falta de espaços, pessoas e partilhas desse cuidado agrava experiências não normalizáveis de corpo e existência. Fatos que - nesses mundos que orientam tais pesquisas e posicionamentos políticos - reforçam um padrão de "normalidade" do funcionamento do corpo e tornam experiências que se distanciam dela muito desafiadoras e abertas a intervençóes que nem sempre melhoram ou dialogam com as vidas em questáo. Vou tentar seguir um pouco desse raciocínio para o próximo movimento reflexivo do texto.

\section{Corpo e subjetividade desorganizados}

Jonas cuidava de sua esposa, Lara. Os dois tinham pouco mais de 60 anos. Lara foi diagnosticada com Alzheimer logo depois de se aposentar. O progresso de seu caso estava sendo muito rápido, o que fazia com que Jonas tivesse de se adaptar a cuidados cada vez mais intensos em um período muito curto. Lara também estava com dificuldades de se adaptar aos medicamentos receitados, o que tornava complexo saber o que era piora da doença e o que era inadequação dos remédios. No primeiro dia que fui ao grupo de cuidadores de pessoas em estágios mais avançados da doença, ouvi Jonas contar que a esposa estava precisando de ajuda para ir ao banheiro. Ela sentia alguma urgência, pedia para ir ao banheiro, mas, chegando lá, não sabia o que precisava fazer. Ele, tentando auxiliá-la, explicava que deveria tirar a parte de baixo da roupa e sentar no vaso. Achando que ela precisava defecar, tentou explicar o tipo de força que ela deveria fazer para tanto. Ela tentou, mas não conseguiu. Jonas ligou a torneira, pensando que talvez ela precisasse urinar e que a água corrente seria um gatilho. Funcionou.

Nesse grupo, as conversas sobre funçóes fisiológicas eram muito frequentes. Falava-se tanto sobre o manejo de fraldas e o auxílio na higiene de seus parentes como sobre como lidar e mediar as dificuldades de segurar e saber como fazer sair urina e fezes. A prisão de ventre era um dilema comum. Ouvi uma cuidadora contar que essa era a terceira vez que precisava fazer uso de um supositório para que seu marido conseguisse defecar. Ela estava chateada com isso, pois o processo todo era muito agressivo - o marido sofria, sentia muita dor, ficava bravo com ela e com as enfermeiras. Disse-nos que já havia tentado mudar a alimentação e nem a quantidade exagerada de fibras havia funcionado. $\mathrm{O}$ ventre cheio e aprisionado também causava muita dor e desconforto. Nesse dia, outra cuidadora aconselhou sobre uma técnica que funcionava com ela. Ela sentava seu parente em uma cadeira de banho (que possui um aparador de fezes e urina) e, com a água morna do chuveirinho, fazia uma massagem na lombar dele. Deixava a água jorrar de cima 
pra baixo e fazia o mesmo movimento com as mãos, na esperança de dialogar com o intestino acerca do rumo e do movimento que ele deveria lembrar.

A demência também gera consequências da ordem do que parecia ser inato no engajamento do corpo humano com determinado funcionamento no mundo. Isso parece ir de acordo com a tese de que corpo é mundo desde o princípio e de que a memória tem uma abrangência bastante ampla na existência. Ao pensar a subjetividade como uma experiência do corpo com a temporalidade, "o passado vigora no presente” (Rabelo, Souza \& Alves, 2012:38) e, assim, a memória vigora no funcionamento presente do corpo. Com isso, quero pensar também que a memória vigora organicamente no presente do corpo. Mas isso se dá em níveis. E, nos casos dos sujeitos com Alzheimer, o vigor do passado no presente é outro.

Talvez possamos pensar em um funcionamento orgânico que perde certas obviedades, estruturas, ou, como prefiro, o passado orgânico que perde vigor no presente. Nesse sentido, fluxos viscerais também parecem ter se constituído organicamente em contato com o mundo, seja por meio de experiência, seja por meio do envolvimento com outrem. De alguma maneira, esses fluxos estruturam mundos, desde que assumamos que existe um espaço para o presente e original e que o passado não vigora sempre da mesma maneira. Isso depende, entre outras contingências, de determinado ordenamento das substâncias, estados afetivos e relações interpessoais, entre outros.

Deleuze \& Guattari (1996), na escrita por “um corpo sem órgãos”, repensam as ideias de organismo, subjetivação e significância a partir do desejo e dos seus agenciamentos. Vou tentar dialogar dentro dessa metáfora, a partir do que consigo compreender, ou melhor, de como esse texto me provoca outras aberturas de olhar. Os autores escrevem no intuito de que se busque ativamente experimentar "um corpo sem órgãos". O problema dos autores não é com os órgãos em si, mas com a conexão necessária, organizada de uma única forma viável, que carregue funcionamentos corretos, adequados, estruturados e produtivos, formulando, assim, o que viria a ser um organismo uno e limitando modos de existência possíveis.

Além do potencial de diminuir experimentaçôes do corpo, a ideia de organismo e suas consequências terapêuticas sugere que existem organismos fechados em si mesmos, ignorando como corpos são tomados de energias, afetaçóes e fluxos de intensidade. Formas de existência podem se dar e se dão em rizomas, em conexôes muitas e diversas que transcendem determinada coerência necessária ao sujeito e ao organismo uno. Primeiro, porque esse organismo não existe como necessidade; ele é, no lugar disso, mantido por uma maquinaria complexa. Depois, porque essas estratégias de normalizaçáo e adequaçáo o prendem a uma 
não agência, ao funcionamento da máquina capitalista, aquela que precisa de organismos produtivos. Ainda, porque ele não dá conta de promover intensidades de preenchimento com um desejo puro, que não seja formado pelo desejo faltoso em busca de um complemento inacessível, pensado pela psicanálise - um desejo que, ao acontecer em devires, cria planos de consistência e campos de imanência. A tese psicanalítica do desejo, para Deleuze \& Guattari (1996), é limitada demais para definir agenciamentos. O desejo pode, em sua perspectiva, criar realidades, promover vida criativa e afetaçóes reais; ele cria imanência e é da ordem do múltiplo. As conexôes de um ser que não é uno, mas que está no mundo em devires com outros, cria singularidades "que não podem mais ser consideradas pessoais" (Deleuze \& Guattari, 1996:16).

A minha opção por substância e não organismo tem algo dessa inspiração. Tentando entrar na metáfora por burlar organismos, acho que é possível justificar por que eu falo de neurônios, sinapses, conexôes em sua potencialidade de relaçóes, inclusive aquelas erráticas ou que aproximam o corpo da morte, mas tenha alguma resistência em falar do cérebro e, mais ainda, em pensar na função do cérebro para o organismo. Isso porque, tirando o protagonismo do cérebro e do organismo, outras coisas podem aparecer aos olhos.

O propósito dos autores é destituir a organização do organismo em cadeias sedimentadas, livrar-se do organismo para voltar a ser corpo. A desorganizaçáo do organismo se transforma em algo positivo, em possibilidade criativa de ser múltiplo e criar outros modos de existência. Corpos podem experimentar modos de existência singulares à normalidade. Normalidade representa, aqui, um ordenamento limitador dos modos de existência: só aqueles que produzem são viáveis.

Mas esse exercício de experimentação, nos autores, depende de determinada prudência, ou funcionamento mínimo do organismo. Aliás, não se trata tanto de alcançar um corpo sem órgãos, mas de buscá-lo em experimentaçóes, as quais tenham a prudência de náo destruir por completo o corpo, ou o sujeito. A morte, a loucura ou a demência são brutais, destroem possibilidades positivadas de devires e modos de vida singulares. Náo se conserva o suficiente, nesses casos, para existir e poder responder à realidade dominante. Contudo, algo que me parece muito relevante nessa reflexão é que um organismo desorganizado, mesmo se cair no vazio da desestratificação brutal, é desejo, mas pode ser desejo suicida, canceroso, fascista.

Uma cuidadora do grupo de idosos com demência em estágio mais avançado nos contou que sua mãe estava sentada em sua cadeira de balanço um dia, depois de um embate das duas para que os dentes dela fossem escovados. Chateada com 
a intervenção em sua higiene bucal, olhou para a filha e disse: "minha filha, eu não sou mais gente!” As duas passaram o dia entristecidas com essa conclusão. Em outro momento, contudo, a mãe disse à filha: "olha pra mim, eu existo sim!" Não ser gente, mas desejar o olhar porque se existe me parece dialogar muito com o que venho tentando discutir acerca da limitaçáo que a normalização dos modos de existência pode fazer com as pessoas que conheci.

Tem algo da relação de cuidado e desse intermundo atravessado pelo cuidado que pode ter mais espaço se agência, impulso ou desejo for pensado em termos de um modo de vida singular e para além da fixidez do sujeito e do organismo. É possível pensar corpo, desejo e agenciamentos que sejam livres da necessidade de existir em um organismo localizado em determinado espaço fixo de subjetivação e significância. Tirar o foco do organismo parece muito relevante para pensar mundos criados de modos possíveis de conexōes entre substâncias.

Mas, talvez, a ideia de acoplamentos e a formulaçáo de um devir situado resolvam um pouco o desconforto, meu, pelo menos, de pensar com a ideia de organismo desorganizado que não chega ao nível da experimentação pretendida pelos autores, já que não existe a possibilidade de prudência com o desejo (seja ele orgânico) que permita conter uma desestratificação demasiado violenta do organismo, da subjetividade e da significância.

Ao dar espaço, em suas formulaçóes teóricas, tanto para os acoplamentos formados por pessoas, mitos, máquinas e seres como para as fricçóes internas a esse processo de acoplar-se e se deixar afetar, Haraway (1991) abre caminhos para refletir sobre o exercício e o posicionamento necessário para esses agenciamentos. Trata-se de pensar um devir "muito situado" (Haraway, 2006) em conexóes que envolvem um posicionamento que se afeta, que leva a sério o exercício de se afetar e fazer de outros, outros significantes, inclusive compartilhando seu sofrimento e seus processos de morte (Haraway, 2009), mas que reconhece e prioriza argumentativamente os limites dos devires e das conexóes.

Situando melhor como essa ideia inspira e encarna teoricamente meu olhar, misturando-se parcialmente com o que consigo enxergar das histórias que conheci e releio: ao observar cuidadoras e pessoas com Alzheimer tentando habitar determinado mundo, observo acoplamentos, compartilhamento orgânico de mundos e disputas cotidianas sobre a vida e a morte. Uma pessoa, ao experimentar os dilemas relatados até aqui, tem dificuldades em viver um cotidiano relativamente estruturado sem o auxílio de pessoas, substâncias e tecnologias. Precisa habitar em conjunto para conseguir se vestir, comer, conversar, se manter viva. Precisa de cuidado. Talvez, se não precisasse manter determinado tipo de vida e cotidiano, precisasse de menos cuidados, mas ir ao mercado, conversar para 
ser compreendido, cozinhar, manter humores tranquilizados, fazer necessidades fisiológicas no banheiro e em horários, náo deixar o corpo morrer, tudo isso demanda outros, demanda suporte.

Observar as alteridades dentro dos acoplamentos e voltar para os sujeitos, ou para os corpos que se diferenciam e se engajam, sendo contíguos, mas também próprios, parece muito importante para pensar como essas vidas são vividas (ou como essas mortes são morridas) e o que está em jogo. Pode haver acoplamentos de cuidadoras com médicos e substâncias que estejam de acordo com o desejo de pessoas com Alzheimer para habitar determinado mundo, ou para ter sensaçóes mais agradáveis; pode haver acoplamentos de cuidadoras com médicos e substâncias para controlar e normalizar seus parentes, sendo o cuidado também um controle do corpo e dos humores do outro. Pode haver acoplamentos de pessoas com Alzheimer e outros para disputar a atenção de seus cuidadores, ou para tentar se livrar dessa atenção; pode haver disputas sobre o que é adequado, de desejos que náo se articulam, mas que concorrem espaços. E tudo isso pode ocorrer entre os mesmos sujeitos, em momentos diferentes do dia.

Pensar os acoplamentos, então, é um caminho para compreender a experiência, dando espaço para as conexóes e substâncias envolvidas. Mas também evidenciar as fricçóes e parcialidades de conexão dentro desses acoplamentos é fundamental para pensá-los e, acredito, para dialogar com o que vinha sendo dito sobre intençôes de normalizar corpos em organismos.

\section{Consideraçóes finais}

Certo dia, ouvi de uma senhora que conheci nos grupos de treinamento da memória que o que tinha de diferente com ela e a fazia frequentar o centro era que "eu tenho um cérebro, ele só não funciona direito". Demências e diagnóstico de Alzheimer se relacionam muito com a temática do cérebro e do funcionamento adequado e inadequado das organicidades e dos sujeitos. Essa senhora resumia bem seu diagnóstico: ela tem um cérebro e algo que desorganiza o funcionamento ideal dele a faz frequentar um centro de saúde. Mas, se o cérebro é o lugarcomum da demência, a amplitude dos relatos e das práticas me pareceu mais difusa em tudo que podemos chamar de corpo, ou nas muitas substâncias que fazem do corpo, corpo, e do sujeito, sujeito a cada dia. Seria difícil falar, então, na especialidade do funcionamento e localização de um órgão. Desviei, ainda, da ideia de funcionamento adequado. Pretendi, embasando-me em um trabalho etnográfico, disputar sentidos dentro das narrativas sobre o Alzheimer. Gostaria de disputar, especialmente, com narrativas que anunciam mortes e promovem estigmas que invisibilizam experiências e mundos de sujeitos que não vivem de 
forma adaptada ao normal e saudável. Nesse sentido, tentei falar algo além do funcionamento adequado ou inadequado de determinado sistema e de seus males fixos decorrentes.

Não quero, com isso, dizer que náo existe sofrimento, inclusive associado aos processos de morte do organismo e de desorganização da subjetividade e da adequação da possibilidade de compartilhar de um universo de sentidos. Pelo contrário, gostaria de sugerir que esse sofrimento seja densamente compreendido e, se possível, compartilhado de maneira mais ampla. Assim, talvez, venha a ser possível pensar em processos de vida com demência e morte com demência que sejam mais atentos e acolhedores com as experiências de sujeitos concretos - tanto os que estão adoecidos como os que se acoplam a eles no cuidado.

Escrever este artigo foi um exercício teórico que manejou conceitos sobre corpo e sujeito em relação a determinado campo. Primeiro, pareceu-me fundamental voltar o sujeito para o corpo e repensar desejo como engajamento no mundo. A noçáo de que uma teoria sobre a subjetividade deve pensar no corpo e em uma amálgama entre biologia e cultura abre espaço para uma discussão acerca do sujeito que tenha em foco o corpo. Mas, observando e acreditando em um desequilíbrio orgânico, sugeri que um deslocamento era importante: pensar sim em como o corpo se organiza em subjetividade. Trouxe, entáo, a perspectiva de que a subjetividade é uma relação do corpo com a temporalidade e que, mesmo que se pensasse em desejo e inconsciente, no caso de sujeitos com Alzheimer era potencializador pensar em impulsos, relações, interafetações que são da ordem de estar no mundo e se envolver nele.

Outro deslocamento do texto foi pensar nesses impulsos no mundo e em uma subjetividade variável, relacionando-se também com articulações de substâncias e de suas várias (des)organizaçooes possíveis. Pensei substância para dar conta da materialidade mesma e de suas organizaçóes orgânicas. Não quero, contudo, pensar em uma substância presa em si mesma, dada ou composta em determinado período da vida - uma substância que, ao se desorganizar, causa mortes não processuais, normaliza demais o vivido e deixa de fora muitas experiências de corpo e subjetividade. Talvez eu esteja pensando substância como Leenhart (1997) entendia que os Canaco experimentavam o mundo. Para eles, o pensamento vem das vísceras; eu diria que abrange o nível das vísceras o engajamento impulsionado no mundo: existir, sentir, pensar e agir no mundo é uma interafetação visceral.

Concordei, então, que o ato perceptivo conecta o corpo à existência e que, assim, a subjetividade é uma relação com o tempo, e o corpo é composto pelo passado, que vigora de maneira variável em cada presente vivido. E, no desequilíbrio específico vivido pelos sujeitos que conheci, o passado vigora menos, 
ou de forma mais desorganizada, em cada presente vivido. Sugeri, então, que se pensasse em organismos, subjetividades e significâncias desorganizadas; em novas configuraçóes das afetaçóes das vísceras; e, ainda, em sujeitos que não fossem fechados em si mesmos no que tange à substância, aos impulsos e aos desejos. Que o desejo pudesse ser fruto de uma singularidade.

Tentei pensar nos acoplamentos que compóem os mundos das pessoas que conheci e de que maneira desejos, ou engajamentos, circulam nesses acoplamentos em relaçáo ao mundo e aos outros que não entendem ou vivem o processo de uma demência. Queria pautar possibilidades de mundos e de vivências que geram sofrimento por serem incompreendidas, por terem que ser, necessariamente, normalizadas a determinado cotidiano e organizaçáo das experiências e corpos. Contudo, me pareceu prudente mencionar as alteridades internas a esses mundos e acoplamentos, pensando nas disputas entre cuidadoras e pessoas com Alzheimer e no sofrimento envolvido em mediar mundos e cuidar de corpos, voltando assim a falar de sujeito e desejo. $\mathrm{O}$ uno é substituído analiticamente pelo múltiplo, mas por meio de conexóes parciais. Gostaria de manter essa tensão, entendo que assim me mantenho situada no que consigo compreender do que vi e ouvi.

Parece-me que um caminho para dizer algo politicamente relevante para o cotidiano das pessoas que conheci é que é cotextualmente necessário continuar falando em sujeitos, fazer isso a partir de um sujeito que é corpo e mundo, um sujeito que é com engajamentos e acoplamentos, e também de corpos que são diversos e que poderiam ter mais potência de se relacionar e trocar afetos e cotidianos caso seus arredores fossem outros. É importante que outros mundos sejam possíveis em ideia, que mortes possam ser pensadas em seus processos e sofrimentos possam ser encarados e compartilhados de forma mais ampla, sem isolar mundos de pessoas que cuidam e que vivem com a demência. Inclusive no exercício de reconhecer que no contexto estudado, por exemplo, viver e morrer têm sido uma tentativa privada, interna às famílias. Algumas delas conseguem se acoplar mais e se isolar menos - isso se relaciona, em uma situação capitalista urbana brasileira, diretamente com as suas possibilidades financeiras e redes de apoio. Nesse sentido, isolar e contar com estratégias privadas promove desigualdades, deixando que alguns processos de morte e vidas náo normalizáveis carreguem níveis de sofrimento evitáveis.

Em suma, compreender e intervir positivamente nessas experiências passa por promover possibilidades de engajamento no mundo, superando isolamento e morte como sentenças de não normalidade. Pode ser um caminho terapêutico investir menos em normalizar mundos e mais em possibilidades de viver melhor outros mundos. E, ainda, promover espaço para acolher sofrimentos e processos 
de morte, bem como refletir sobre eles. Não falar ou privatizar a vivência de sofrimentos e mortes parece intensificar aspectos negativos dessas experiências, no lugar de refletir de forma responsiva sobre possíveis acolhimentos.

\author{
Recebido em 09/10/2016
}

Aprovado em 09/12/2017

Cíntia Liara Engel é doutoranda em antropologia social pela Universidade de Brasília, mestra e graduada em sociologia pela mesma universidade. Possui especialização em bioética, experiência e interesse nos temas de corpo, saúde, envelhecimento, adoecimento, demência, Alzheimer, cuidado e gênero. Contato: cintiaengel@gmail.com.

\title{
Notas
}

1. O projeto de pesquisa passou pelo sistema CEP/Conep e foi aprovado. Não utilizei de Termos de Consentimento Livre e Esclarecido porque julguei que eles poderiam burocratizar e atrapalhar a dinâmica dos grupos, além de não parecer um instrumento adequado para pessoas diagnosticadas com demência, por razóes óbvias. Pedia o consentimento oralmente, no início de cada sessão dos grupos. Em minha dissertação, discorro de forma detalhada sobre o processo de aprovação do projeto por distintos comitês, assim como sobre os espaços e as dinâmicas de funcionamento dos grupos (Engel, 2013).

2. Pelo que compreendi, esse tipo de demência é ocasionado por acidentes vasculares, e é possível observar manchas no cérebro quando feitos os exames de imagem.

3. Para discutir mais a fundo formulaçóes hegemônicas de um paradigma cerebralista, o texto precisaria dar mais espaço para narrativas que circulam sobre o cérebro na demência e como elas orientam critérios de diagnóstico, produção de medicamentos e organizaçôes de pacientes e cuidadoras. Decidi, contudo, percorrer outro caminho neste artigo. Minha expectativa é nuançar a naturalização do cérebro enquanto órgão fechado em si mesmo e das funções normais do cérebro para a realização do sujeito no debate sobre as demências a partir de uma etnografia sobre experiências. Minha proposta é me aproximar da experiência com demência levando em conta novidades com o corpo e com o sujeito nas suas relaçóes e trocas com outros e, a partir disso, pensar emaranhados de subjetividades e substâncias sem estabilizá-los em explicaçôes que localizam as manifestações físicas e os engajamentos subjetivos com o mundo

4. Os nomes são fictícios e não são os mesmos que utilizei na dissertação. Tento, com isso, garantir melhor o anonimato das pessoas que conheci. 


\section{Referências}

AZIZE, Rogerio Lopes. 2011. "O cérebro como órgão pessoal: uma antropologia de discursos neurocientíficos”. Trabalho Educação Saúde, 8(3):563-574.

BALLENGER, Jesse et al. 2009. Treating dementia: do we have a pill for it? Baltimore: Johns Hopkins University Press.

CHATTERJI, Roma. 1998. "An ethnography of dementia". Culture, Medicine and Psychiatry, 22(3):355-382.

. 2006. "Normality and difference: institutional classification and the constitution of subjectivity in a Dutch nursing home". In: Annette Leibing \& Lawrence Cohen. Thinking about dementia: culture, loss, and the anthropology of senility. New Jersey: Rutgers University Press. pp. 218-240.

DELEUZE, Gilles \& GUATTARI, Félix. 1996. "28 de novembro de 1947 - como criar para si um corpo sem órgãos". In: . Mil platôs: capitalismo e esquizofrenia. Rio de Janeiro: Ed. 34. v. 3, pp. 8-28.

DESCOLA, Philippe. 2014. "Modes of being and forms of predication". Hau: Journal of Ethnographic Theory, 4(1):271-280.

DINIZ, Debora \& BARBOSA, Livia. 2010. "Pessoas com deficiência e direitos humanos no Brasil”. In: Gustavo Venturi (org.). Direitos humanos: percep̧ôes da opiniāo públicaanálises de pesquisa nacional. Brasília: Secretaria de Direitos Humanos. pp. 207-217.

ENGEL, Cíntia. 2013. Doença de Alzheimer e cuidado familiar. Dissertação de mestrado, Universidade de Brasília.

FERIANI, Daniela. 2017. Entre sopros e assombros: estética e experiência na doença de Alzheimer. Tese de Doutorado, Universidade de Campinas.

FLEISCHER, Soraya. No prelo. Descontrolada: uma etnografia dos problemas de pressão. São Carlos: EdUFSCar.

FOX, Patrick. 1989. "From senility to Alzheimer's disease: the rise of the Alzheimer's disease movement". Milbank Quarterly, 67(1):58-102.

GRAHAM, Janice. 2006. "Diagnosing dementia: epidemiological and clinical data as cultural text". In: Annette Leibing \& Lawrence Cohen. Thinking about dementia: culture, loss, and the anthropology of senility. New Jersey: Rutgers University Press. pp. 80-106.

HARAWAY, Donna. 1991. "Simians, cyborgs and women: the reinvention of nature". New York: Routledge. 
HARAWAY, Donna. 2006. "When we have never been human, what is to be done? Interview with Donna Haraway”. Theory, Culture \& Society, 23(7-8): 135-158.

INGOLD, Tim. 2011. Being alive: essays on movement, knowledge and description. New York: Routledge.

KAFER, Alison. 2013. Feminist, queer, crip. Bloomington: Indiana University Press.

KONTOS, Pia. 2005. "Embodied selfhood in Alzheimer's disease: rethinking personcentred care". Dementia, 4(4):553-570.

KONTOS, Pia \& NAGLIE, Gary. 2009. "Tacit knowledge of caring and embodied selfhood". Sociology of Health and Illness, 31(5):688-704.

KONTOS, Pia et al. 2011. "Dementia care at the intersection of regulation and reflexivity: a critical realist perspective". Journals of Gerontology - Series B Psychological Sciences and Social Sciences, 66 B(1):119-128.

LEENHARDT, Maurice. 1997. Do Kamo: person and myth in the Melanesian world. Chicago and London: The University of Chicago Press. Publicado originalmente em 1947.

LEIBING, Annette. 2017. "Successful selves? Heroic tales of Alzheimer's disease and personhood in Brazil". In: Sarah Lamb (ed.). Successful aging? Global perspectives on a contemporary obsession. New Jersey: Rutgers University Press. pp. 203-217.

. 2006. "Divided gazes: Alzheimer's disease, the person within, and death in life". Annette Leibing \& Lawrence Cohen. Thinking about dementia: culture, loss, and the anthropology of senility. New Jersey: Rutgers University Press. pp. 240-269.

. 1999. "Olhando para trás: os dois nascimentos da doença de Alzheimer e a senilidade no Brasil”. Estudos Interdisciplinares Envelhecimento, 1:37-56.

LOCK, Margaret. 2013. The Alzheimer conundrum: entanglements of dementia and aging. New Jersey: Princeton University Press.

MERLEAU-PONTY, Maurice. 2006. Fenomenologia da percepção. São Paulo: Martins Fontes. Publicado originalmente em 1945.

. 2015. O primado da percepção e suas consequências filosóficas. Belo Horizonte: Autêntica.

MOORE, Henrietta. 2007. The subject of anthropology: gender, symbolism and psychoanalysis. Cambridge and Malden: Polity Press. 
RABELO, Miriam C. M., SOUZA, Iara Maria de Almeida \& ALVES, Paulo César (org.). 2012. Trajetórias, sensibilidades, materialidades: experimentaçôes com a fenomenologia. Salvador: EDUFBA.

ROSE, Nicolas. 2007. The politics of life itself: biomedicine, power, and subjectivity in the twenty-first century. New Jersey: Princeton University Press.

SINGER, Judy. 1999. "Why can't you be normal for once in your life?' From a 'problem with no name' to the emergence of a new category of difference”. In: Mairian Corker \& Sally French (org.). Disability discourse. Buckingham, Philadelphia: Open University Press. pp. 59-67.

VIANNA, Luciano von der Goltz. 2015. "O que pode uma ontologia demente: vitalizando materiais produtores de humanos em uma etnografia sobre a doença de Alzheimer". In: Cecilia Anne Mccallum \& Fabíola Rohden (org.). Corpo e saúde na mira da antropologia: ontologias, práticas, traduçôes. Salvador, EDUFBA: ABA. pp. 301-341.

VIDAL, Francisco; ORTEGA, Francisco. 2017. Being brains: making the cerebral subject. New York: Fordham University Press. 


\section{Resumo}

Em 2012, acompanhei etnograficamente grupos terapêuticos para pessoas com Alzheimer e para cuidadoras e cuidadores familiares em um serviço oferecido pelo Hospital Universitário de Brasília. Fui a campo para compreender o que acontecia com sujeitos e ouvir suas narrativas sobre os dilemas da doença, mas acabei por me envolver com relaçóes, substâncias e trocas que desestabilizaram algumas noçóes que carregava acerca de sujeitos, corpos, cérebro, organismos e mundos. Este artigo é uma tentativa de, a partir dos sintomas, reclames e modos de se comunicar criados, discutir algumas dessas noçóes e suas instabilidades. Inicio com uma perspectiva sobre o que seria a constituição de subjetividades encarnadas. Percebo, contudo, que algumas coisas deixam de ser ditas e que pensar em como corpo se organiza em subjetividade e se engaja no mundo abre outros caminhos. Tento debater com a ideia de um organismo que possui um funcionamento normal necessário para estar no mundo, olhando para as desorganizações desse funcionamento, o que me faz também pensar em substâncias, agenciamentos, vontades e engajamento do corpo para além do normal. Passo, entáo, a tensionar essas outras existências e mundos compartilhados a partir de corpos que convivem, criam e resistem a técnicas de estabilizações; faço isso dando espaço para as várias disputas envolvidas nesse processo. Em resposta ao cérebro e suas funçôes corretas, argumento em torno de substâncias em relação.

Palavras-chave: corpo, Alzheimer, sujeitos, substância e normalidade.
In 2012, I did an ethnographical research on therapeutic groups for people with Alzheimer's and their family caregivers on a service offered by the University Hospital of Brasilia. I went to the field with the aim of understanding what happened to the subjects and hear their stories about the dilemmas of the disease, but I realize that I was dealing with relationships, substances and exchanges that were destabilizing some of my preconceptions about subjects, bodies, brains and worlds. This article is an attempt to discuss some of these preconceived notions and their instabilities in light of the symptoms, complaints and ways of communicating created. I begin with the perspective of embodied subjectivities. I notice, however, that some things are still not clear, so I also reflect about how the body is organized in subjectivity and engages with the world. I try to debate with the idea of a body that has a normal operation needed to be in the world, looking at the disorganization of this operation, which makes me think about substances, engagements, wills and body beyond the normal. I think about other existences and worlds shared from bodies that coexist, create and resist technical attempts of stabilization, giving also space to the various disputes involved in this process. In response to the brain and their proper function, I discuss around substances in relations.

Key-words: body, Alzheimer, subjects, substance and normality. 